\title{
Pituitary-Adrenal Responses to Acute Hypoxemia During and After Maternal Dexamethasone Treatment in Sheep
}

\author{
JUANITA K. JELLYMAN, DAVID S. GARDNER, HUGH H.G. MCGARRIGLE, \\ ABIGAIL L. FOWDEN, AND DINO A. GIUSSANI \\ Department of Physiology, University of Cambridge, Cambridge CB2 3EG, UK
}

\begin{abstract}
ABST
The effects of maternal dexamethasone treatment on hypo-
thalamic-pituitary-adrenal axis function were determined during
basal and hypoxemic conditions in maternal and fetal sheep.
Under halothane, ewes and their fetuses were catheterized at
$117 \mathrm{~d}$ gestation (term $=145 \mathrm{~d})$. Starting at $124 \mathrm{~d}$, the ewes
received i.m. injections of two doses of either dexamethasone $(12$
mg) or saline at $24-\mathrm{h}$ intervals. All animals experienced one
episode of hypoxemia when the dexamethasone was present in
the maternal and fetal circulations [125 $\pm 1 \mathrm{~d}(\mathrm{H} 1)]$ and a second
episode of hypoxemia when the steroid was no longer detectable
in either the maternal or fetal circulations [128 $\pm 1 \mathrm{~d}(\mathrm{H} 2)]$. The
fall in partial pressure of oxygen in arterial blood in response to
hypoxia was similar in the two episodes in both the fetal and the
maternal blood. Maternal dexamethasone treatment diminished
maternal and fetal basal plasma cortisol but not ACTH during the
normoxic period of H1 but not H2. In control animals, hypox-
emia induced increases in fetal but not maternal ACTH and
cortisol concentrations. In dexamethasone-treated animals, ma-
\end{abstract}
Since the pioneering discovery of Liggins (1) that glucocorticoids are essential for the maturation of fetal systems in preparation for extrauterine life, synthetic glucocorticoids, such as dexamethasone, have been used routinely in human clinical practice to treat pregnant women who are at risk of preterm delivery (2-4). Such prophylactic treatment mimics the normal prepartum increase in endogenous cortisol output by the fetal adrenal that switches tissue accretion to differentiation (5). Antenatal glucocorticoid treatment has resulted in significant decreases in the incidence of respiratory distress syndrome, necrotizing enterocolitis, intraventricular hemorrhage, and neonatal mortality associated with preterm birth $(3,6)$.

Received October 30, 2003; accepted April 1, 2004.

Correspondence: Dino A. Giussani, Ph.D., Department of Physiology, University of Cambridge, Downing Street, Cambridge CB2 3EG, UK; e-mail: dag26@cam.ac.uk

This work was supported by Tommy's-the Baby Charity, UK.

J.K.J is currently a fellow of the New Zealand Foundation for Research and Technology, and D.A.G. is currently a Fellow of the Lister Institute for Preventive Medicine, UK.

DOI: 10.1203/01.PDR.0000145253.92052.60 ternal ACTH and cortisol concentrations also remained unchanged from baseline in both $\mathrm{H} 1$ and $\mathrm{H} 2$. In contrast, fetal plasma ACTH and cortisol responses to hypoxemia were significantly suppressed during $\mathrm{H} 1$ but not $\mathrm{H} 2$. Correlation of fetal plasma ACTH and cortisol concentrations suggested diminished cortisol output without a change in adrenocortical responsiveness in dexamethasone-treated fetuses during $\mathrm{H} 1$ but not $\mathrm{H} 2$. Maternal treatment with dexamethasone transiently suppressed maternal and fetal basal hypothalamic-pituitary-adrenal axis function and the fetal plasma ACTH and cortisol responses to acute hypoxemia in sheep. (Pediatr Res 56: 864-872, 2004)
Abbreviations
CBG, corticosteroid-binding globulin
dGA, days of gestational age
HPA, hypothalamo-pituitary-adrenal
POMC, pro-opiomelanocortin

Despite the clear benefits of antenatal glucocorticoid therapy, concerns have been expressed about the safety of the current dosing regimen, in particular with regards to maternal and fetal adrenal suppression resulting from negative feedback by the synthetic steroid (4). In addition, the effects of synthetic glucocorticoids on the fetal defense responses to hypoxemic insults have been identified by the National Institutes of Health in the United States as an area of research needed to guide intrapartum clinical care (4). This is important for two reasons. First, the ovine hypothalamic-pituitary-adrenal (HPA) axis is activated in response to acute hypoxemia in the mother and the fetus and plays an integral role in the fetal defense response to acute hypoxemia (7). Second, episodes of acute hypoxemia are common during pregnancy, in particular during labor and delivery (8). Because antenatal glucocorticoids are given to pregnant women who are most at risk of preterm delivery, it is likely that delivery and therefore episodes of acute hypoxemia will occur either during or shortly after maternal steroid treatment. 
Previous studies in the ovine fetus during late gestation suggested that the timing of an episode of acute hypoxemia relative to antenatal treatment with glucocorticoids might determine the balance between the maturational and the suppressive effects of these steroids on the fetal HPA axis (9). Direct infusion of the ovine fetus with low doses of dexamethasone during late gestation has been shown to suppress pituitaryadrenal responses to an episode of acute hypoxemia that occurred during treatment (10). However, a similar hypoxemic challenge that occurred $2 \mathrm{~d}$ after treatment, in the absence of glucocorticoid negative feedback, resulted in enhanced adrenal cortisol output without alterations in adrenal cortical sensitivity to ACTH (9). However, in clinical practice, synthetic glucocorticoids are administered to the mother and not to the fetus. In addition, in contrast to the effect of antenatal glucocorticoid therapy on the fetal HPA axis, little attention has been paid to the effects of this treatment on maternal pituitary-adrenal responses. Hence, this study determined the effects of maternal treatment with dexamethasone in doses and dose intervals used in human clinical practice on both maternal and fetal pituitaryadrenal functions during basal conditions and in response to acute hypoxemia in sheep.

\section{METHODS}

\section{Surgical Preparation}

Seventeen Welsh Mountain ewes that were carrying fetuses of known gestational age were used in the study. All procedures were performed under the UK Animals (Scientific Procedures) Act, 1986. All food but not water was withdrawn from the animals for $24 \mathrm{~h}$ before surgery.

Surgery was performed under aseptic conditions at $117 \pm$ $1 \mathrm{~d}$ of gestation (dGA; term is $\sim 145 \mathrm{dGA}$ ). Anesthesia was induced with sodium thiopentone $(20 \mathrm{mg} / \mathrm{kg}$ i.v. Intraval Sodium; Rhone Mérieux, Dublin, Ireland) and maintained with 1 to $2 \%$ halothane in $50: 50 \mathrm{O}_{2} / \mathrm{N}_{2} \mathrm{O}$. In brief, after abdominal and uterine incisions, the fetal head was exteriorized for insertion of a catheter (i.d. $0.86 \mathrm{~mm}$, o.d. $1.52 \mathrm{~mm}$; Critchly Electrical Products, NSW, Australia) into a carotid artery with the tip of the catheter extended to the ascending aorta. The catheter was filled with heparinized saline (100 i.u. heparin $/ \mathrm{ml}$ in $0.9 \%$ $\mathrm{NaCl}$ ) and plugged with a brass pin, and the uterine incision was closed in layers. A Teflon catheter was inserted into the maternal femoral artery and advanced into the descending aorta. A third catheter was placed in the amniotic cavity. Antibiotics were administered to the fetus through the carotid artery (300 mg of ampicillin; Penbritin, SmithKline-Beecham Animal Health, Surrey, UK) and into the amniotic cavity (300 $\mathrm{mg}$ of ampicillin). All catheters were exteriorized through a keyhole incision in the maternal flank and housed in a pouch sutured to the mother's skin.

\section{Postoperative Care}

Animals were housed in individual pens with access to hay and water ad libitum. Concentrates were fed twice daily (100 g; Sheep Nuts \#6; H\&C Beart Ltd., Kings Lynn, UK). All ewes received antibiotics $(0.20-0.25 \mathrm{mg} / \mathrm{kg}$ i.m. Depocillin; Myco- farm, Cambridge, UK) immediately after surgery and daily for $3 \mathrm{~d}$. Patency of fetal vascular catheters was maintained by a slow continuous infusion of heparinized saline (100 i.u. hepa$\mathrm{rin} / \mathrm{ml}$ at $0.1 \mathrm{~mL} / \mathrm{h}$ in $0.9 \% \mathrm{NaCl})$ containing antibiotic (10 $\mathrm{mg} / \mathrm{ml}$ of benzylpenicillin; Crystapen, Schering-Plough, Animal Health Division, Welwyn Garden City, UK).

\section{Experimental Procedures}

At least $5 \mathrm{~d}$ after surgery, at $122 \pm 1 \mathrm{dGA}$, the animals were divided randomly into two experimental groups. Ten ewes received $2 \times 12-\mathrm{mg}$ injections of dexamethasone (dexamethasone sodium phosphate; Merck Sharpe, Dohme Ltd., Herts, UK) in $2 \mathrm{~mL}$ of saline $(0.9 \% \mathrm{NaCl}) 24 \mathrm{~h}$ apart. Seven ewes received two injections of $2 \mathrm{~mL}$ of saline $24 \mathrm{~h}$ apart to serve as age-matched sham controls.

All ewes and their fetuses were subjected to two separate episodes of acute hypoxemia, induced by reducing the maternal fraction of inspired oxygen, at $125 \pm 1 \mathrm{dGA}$ ( $8 \mathrm{~h}$ after the second maternal injection; hypoxemia 1 (H1)] and again at 128 \pm 1 dGA [3 d after the second dexamethasone injection; hypoxemia 2 (H2)]. The rationale for the first episode of acute hypoxemia was to determine whether HPA axis responses to acute stress were affected when dexamethasone was present in the maternal and fetal circulations. The acute hypoxemic challenge was performed $8 \mathrm{~h}$ after the second injection at a time when fetal plasma concentrations of dexamethasone were similar to those measured during direct fetal treatment (10). The rationale for the second episode of acute hypoxemia was to determine the long-term effects of glucocorticoid exposure after the dexamethasone had cleared from both the maternal and the fetal circulations. The protocol for acute hypoxemia involved a 3-h experiment consisting of $1 \mathrm{~h}$ of normoxia, $1 \mathrm{~h}$ of hypoxemia, and $1 \mathrm{~h}$ of recovery. In brief, for $1 \mathrm{~h}$, air was passed at a rate of $\sim 40 \mathrm{~L} / \mathrm{min}$ into a large, transparent, polythene bag placed over the ewes' head. After this control period, maternal and fetal hypoxemia was induced by changing the concentrations of gases breathed by the ewe to $9 \% \mathrm{O}_{2}$ in $\mathrm{N}_{2}$ with 2 to $3 \% \mathrm{CO}_{2}$. This mixture was designed to reduce maternal and fetal arterial partial pressure of oxygen in arterial blood to $\sim 35$ and $12 \mathrm{~mm} \mathrm{Hg}$, respectively, while maintaining arterial isocapnia. After the 1-h period of hypoxemia, the ewe was returned to breathing air for the 1-h recovery period.

\section{Measurements and Biochemical Analyses}

During the hypoxemia protocols, arterial blood samples (4 $\mathrm{mL}$ ) were collected at 15 and $45 \mathrm{~min}$ of normoxia, after 15 and $45 \mathrm{~min}$ of hypoxemia, and after $45 \mathrm{~min}$ of recovery. The descending aortic blood samples $(0.4 \mathrm{~mL})$ were drawn into sterile syringes and analyzed for measurement of arterial blood gases, percent saturation of $\mathrm{O}_{2}$ in $\mathrm{Hb}, \mathrm{Hb}$ concentration, and acid/base status using an ABL5 blood gas analyzer and OSM2 hemoximeter (Radiometer, Copenhagen, Denmark). Measurements in maternal and fetal blood were corrected to 38 and $39.5^{\circ} \mathrm{C}$, respectively. All blood samples for hormone analysis were collected into $\mathrm{K}^{+} /$EDTA-treated tubes, kept on ice, and centrifuged at $4000 \mathrm{rpm}$ for $4 \mathrm{~min}$ at $4^{\circ} \mathrm{C}$. Plasma samples were stored at $-70^{\circ} \mathrm{C}$ until analyses. 


\section{ACTH}

Maternal and fetal plasma ACTH concentrations were measured using a commercially available double antibody ${ }^{125}$ I RIA kit (Incstar Ltd, Wokingham, UK). The lower limit of detection for the assay was between 10 and $25 \mathrm{pg} / \mathrm{mL}$. The intra-assay coefficients of variation for two plasma pools (37 and 150 $\mathrm{pg} / \mathrm{ml}$ ) were 3.6 and $4.1 \%$, respectively. The interassay coefficient of variation was $8.4 \%$. The cross-reactivities for the assay were $<0.01 \%$ for $\alpha$-MSH, $\beta$-endorphin, $\beta$-lipotrophin, leucine enkephalin, methionine enkephalin, bombesin, calcitonin, PTH, FSH, AVP, oxytocin, and substance P.

\section{CORTISOL}

Maternal and fetal plasma cortisol concentrations were measured by RIA validated for use in ovine plasma, as described previously (11). The lower limit of detection for the assay was $1.0-1.5 \mathrm{ng} / \mathrm{ml}$. The intra- and interassay coefficients of variations were 5.3 and $7.8 \%$, respectively. The cross-reactivities of the antiserum at $50 \%$ binding with other cortisol-related compounds were $0.5 \%$ cortisone, $2.3 \%$ corticosterone, $0.3 \%$ progesterone, and $4.6 \%$ deoxycortisol.

\section{DEXAMETHASONE}

Plasma dexamethasone levels were measured after ether extraction using tritium-labeled dexamethasone as tracer, as described previously (10). All values were corrected for recovery $(86 \%)$. The interassay coefficients of variation for three control plasma pools $(1.8,5.4$, and $26.7 \mathrm{nmol} / \mathrm{L})$ were 14.6 , 9.3 , and $8.2 \%$, respectively. The lower detection limit of the assay was $0.2 \mathrm{nmol} / \mathrm{L}$. The antidexamethasone antiserum showed a $1.6 \%$ cross-reactivity against cortisol and crossreactivities of $<0.5 \%$ against 11 -deoxycortisol, corticosterone, testosterone, progesterone, and estriol.

\section{STATISTICAL ANALYSES}

Values for all variables are expressed as means \pm SEM. All measured variables were first analyzed for normality of distribution. All data obtained were parametric and were analyzed using two-way ANOVA with repeated measures (Sigma Chemical Co.-Stat; SPSS Inc, Chicago, IL) followed by an appropriate post hoc test. A comparison between the slopes and intercepts of regression curves was conducted according to Armitage and Berry (12). For all comparisons, statistical significance was accepted at $p<0.05$.

\section{RESULTS}

Dexamethasone concentrations. In saline-injected ewes and their fetuses, dexamethasone immunoreactivity was undetectable in the circulation throughout the experiment. In contrast, plasma concentrations of dexamethasone were significantly elevated in dexamethasone-injected ewes $(6.83 \pm 0.20 \mathrm{nmol} / \mathrm{L}$; $n=6)$ and their fetuses $(3.83 \pm 0.32 \mathrm{nmol} / \mathrm{L} ; n=6)$ during H1. No dexamethasone could be detected in either the maternal or the fetal circulations at the time of $\mathrm{H} 2$.
Blood gas and metabolic status. Values for maternal basal arterial $\mathrm{pH}, \mathrm{PCO}_{2}, \mathrm{Po}_{2}$, percentage saturation of $\mathrm{Hb}$, percentage hematocrit, and concentrations of $\mathrm{Hb}$ were similar in salineand dexamethasone-treated ewes during $\mathrm{H} 1$ and $\mathrm{H} 2$ (Table 1). Values for fetal arterial $\mathrm{pH}, \mathrm{PCO}_{2}, \mathrm{PO}_{2}$, and percentage saturation of $\mathrm{Hb}$ were similar in saline- and dexamethasone-treated fetuses during $\mathrm{H} 1$ and $\mathrm{H} 2$ (Table 2). Whereas fetal basal concentrations of $\mathrm{Hb}$ and percentage hematocrit were similar in saline- and dexamethasone-treated fetuses during $\mathrm{H} 1$, both of these were significantly decreased in dexamethasone-treated fetuses during the basal period of $\mathrm{H} 2$ (Table 2).

In the mother, acute hypoxemia induced significant reductions in maternal arterial $\mathrm{PO}_{2}$ and percentage saturation of $\mathrm{Hb}$ and significant increases in plasma concentrations of $\mathrm{Hb}$ during both $\mathrm{H} 1$ and $\mathrm{H} 2$ (Table 1). These alterations occurred without significant changes in maternal arterial $\mathrm{pH}, \mathrm{PCO}_{2}$, or percentage hematocrit. During recovery, a reduction from baseline occurred in maternal arterial $\mathrm{PCO}_{2}$, and maternal arterial $\mathrm{Po}_{2}$ tended to shoot above prehypoxemic levels. All other variables returned toward baseline values (Table 1).

In the fetus, acute hypoxemia induced significant reductions in arterial $\mathrm{Po}_{2}$ and percentage saturation of $\mathrm{Hb}$, with significant increases in plasma concentrations of $\mathrm{Hb}$, but without alterations in arterial $\mathrm{PCO}_{2}$ or hematocrit during $\mathrm{H} 1$ and $\mathrm{H} 2$ (Tables 1 and 2). Hypoxemia elicited mild progressive acidemia in all fetuses. The magnitude of the fetal acidemic response to acute hypoxemia was significantly greater in dexamethasone compared with saline groups during $\mathrm{H} 1$ but not $\mathrm{H} 2$. Whereas fetal arterial $\mathrm{pH}$ remained lower than baseline, all other variables returned toward baseline during recovery (Table 2).

ACTH and cortisol. In dexamethasone animals, basal plasma concentrations of ACTH tended to be lower in the maternal and fetal circulations during $\mathrm{H} 1$; however, these differences did not reach statistical significance. During H2, basal plasma concentrations of ACTH were not significantly different in saline or dexamethasone groups in either the maternal or the fetal circulations. Conversely, both maternal and fetal plasma concentrations of cortisol were significantly lower during the basal period of $\mathrm{H} 1$ but not of $\mathrm{H} 2$ in dexamethasonecompared with saline-treated animals (Figs. 1 and 2).

During the acute hypoxemic periods of $\mathrm{H} 1$ and $\mathrm{H} 2$, there were no significant alterations from baseline in the maternal plasma concentrations of ACTH or cortisol in any animal (Fig. 1). In contrast, in the saline fetuses, fetal plasma concentrations of ACTH and cortisol were significantly increased for the duration of both hypoxemic challenges and remained elevated during the recovery periods. In dexamethasone-treated fetuses, there was no hypoxemia-induced increase in plasma ACTH or cortisol during H1. However, during H2, the ACTH and cortisol responses had returned and were similar in magnitude to those seen in saline-treated fetuses (Figs. 1 and 2).

When the relationship between the fetal plasma ACTH and cortisol concentrations was analyzed for each of the two episodes of acute hypoxemia, the intercept but not the slope of the relationship was significantly lower in dexamethasone than saline fetuses during $\mathrm{H} 1$ (Fig. 3A). No differences in the relationship between fetal plasma ACTH and cortisol concentrations were observed during $\mathrm{H} 2$ (Fig. $3 B$ ). The relationship 
Table 1. Arterial blood gas and metabolic status during $H 1(A)$ and $H 2(B)$ in saline-and dexamethasone-treated ewes

\begin{tabular}{|c|c|c|c|c|c|c|}
\hline & \multicolumn{2}{|c|}{ Baseline } & \multicolumn{2}{|c|}{ Hypoxemia } & \multicolumn{2}{|c|}{ Recovery } \\
\hline \multicolumn{7}{|l|}{ H1 } \\
\hline Saline & $7.50 \pm 0.01$ & $7.50 \pm 0.01$ & $7.49 \pm 0.02$ & $7.49 \pm 0.01$ & $7.50 \pm 0.02$ & $7.48 \pm 0.01$ \\
\hline Dexamethasone & $7.53 \pm 0.02$ & $7.52 \pm 0.01$ & $7.52 \pm 0.02$ & $7.53 \pm 0.02$ & $7.53 \pm 0.02$ & $7.51 \pm 0.02$ \\
\hline \multicolumn{7}{|l|}{$\mathrm{PaCO}_{2}(\mathrm{~mm} \mathrm{Hg})$} \\
\hline \multicolumn{7}{|l|}{$\mathrm{PaO}_{2}(\mathrm{~mm} \mathrm{Hg})$} \\
\hline Saline & $97 \pm 2$ & $101 \pm 2$ & $37 \pm 2 *$ & $37 \pm 2 *$ & $104 \pm 2$ & $100 \pm 2$ \\
\hline Dexamethasone & $96 \pm 1$ & $96 \pm 2$ & $35 \pm 1 *$ & $35 \pm 1^{*}$ & $100 \pm 2$ & $97 \pm 2$ \\
\hline \multicolumn{7}{|l|}{$\mathrm{SatHb}(\%)$} \\
\hline Saline & $98.8 \pm 0.5$ & $99.0 \pm 0.5$ & $60.3 \pm 4.9^{*}$ & $59.4 \pm 3.9^{*}$ & $99.3 \pm 1.6$ & $100.0 \pm 0.9$ \\
\hline Dexamethasone & $96.0 \pm 1.2$ & $95.3 \pm 1.2$ & $54.5 \pm 4.1 *$ & $53.5 \pm 3.4^{*}$ & $93.6 \pm 2.7$ & $95.0 \pm 1.8$ \\
\hline Saline & $27 \pm 1$ & $27 \pm 1$ & $28 \pm 1$ & $29 \pm 1$ & $28 \pm 1$ & $28 \pm 1$ \\
\hline Dexamethasone & $29 \pm 1$ & $28 \pm 1$ & $30 \pm 1$ & $30 \pm 1$ & $29 \pm 1$ & $28 \pm 1$ \\
\hline \multicolumn{7}{|l|}{$\mathrm{H} 2$} \\
\hline \multicolumn{7}{|l|}{$\mathrm{pH}_{\mathrm{a}}$} \\
\hline Saline & $7.49 \pm 0.01$ & $7.49 \pm 0.01$ & $7.49 \pm 0.01$ & $7.50 \pm 0.01$ & $7.52 \pm 0.01$ & $7.48 \pm 0.01$ \\
\hline Dexamethasone & $7.51 \pm 0.01$ & $7.50 \pm 0.01$ & $7.51 \pm 0.01$ & $7.49 \pm 0.01$ & $7.53 \pm 0.01$ & $7.48 \pm 0.01$ \\
\hline \multicolumn{7}{|l|}{$\mathrm{PaCO}_{2}(\mathrm{~mm} \mathrm{Hg})$} \\
\hline Saline & $37 \pm 1$ & $35 \pm 1$ & $36 \pm 2$ & $36 \pm 1$ & $31 \pm 1^{*}$ & $35 \pm 1$ \\
\hline Dexamethasone & $35 \pm 1$ & $32 \pm 1$ & $36 \pm 1$ & $37 \pm 1$ & $33 \pm 2$ & $36 \pm 1$ \\
\hline \multicolumn{7}{|l|}{$\mathrm{PaO}_{2}(\mathrm{~mm} \mathrm{Hg})$} \\
\hline Saline & $97 \pm 2$ & $99 \pm 1$ & $38 \pm 2 *$ & $37 \pm 3^{*}$ & $105 \pm 1 *$ & $100 \pm 1$ \\
\hline Dexamethasone & $98 \pm 2$ & $98 \pm 3$ & $35 \pm 1 *$ & $35 \pm 1 *$ & $104 \pm 2 *$ & $97 \pm 2$ \\
\hline \multicolumn{7}{|l|}{ SatHb $(\%)$} \\
\hline
\end{tabular}

Values are means \pm S.E.M. for 7 saline and 10 dexamethasone treated ewes. Arterial blood samples were taken at 15 and 45 minutes of normoxia $(\mathrm{N})$, hypoxemia $(\mathrm{H})$ and recovery $(\mathrm{R})$. Statistical differences $(\mathrm{P}<0.05)$ are; *versus normoxia (Two Way repeated measures $(\mathrm{RM})$ ANOVA + Tukey test). Blood gas values were corrected to $38^{\circ} \mathrm{C} . \mathrm{pH}_{\mathrm{a}}$, arterial $\mathrm{pH}$; SatHb, saturation of hemoglobin; [Hb], concentration of hemoglobin; Hct, hematocrit.

between maternal ACTH and cortisol concentrations during acute hypoxemia could not be analyzed because of the narrow range of maternal ACTH values.

\section{DISCUSSION}

This study showed that maternal administration of dexamethasone in doses and dose intervals used in human clinical practice transiently depressed basal cortisol concentrations in both the mother and the fetus without an apparent effect on basal ACTH concentrations. In control animals, acute hypoxemia induced significant increases in fetal but not maternal ACTH and cortisol concentrations. In contrast, fetal plasma ACTH and cortisol responses to acute hypoxemia were significantly suppressed when the dexamethasone was present in the fetal circulation but not $3 \mathrm{~d}$ later, when the dexamethasone had cleared from the maternal and the fetal circulations. The relationship between fetal plasma ACTH and cortisol concentrations showed that cortisol output was diminished without an apparent change in adrenocortical ACTH sensitivity when dexamethasone was present in the fetal circulation.

Dexamethasone concentrations. The plasma concentrations of dexamethasone measured in fetal sheep were similar to values measured in human umbilical cord blood within $24 \mathrm{~h}$ of a course of antenatal glucocorticoid therapy $(13,14)$. Although maternal injection with dexamethasone would have exposed the ewe and the fetus to initially high then rapidly decreasing concentrations of synthetic glucocorticoid, the plasma concentrations in maternal and fetal blood at the onset of $\mathrm{H} 1$ were similar to those reported previously $8 \mathrm{~h}$ after injection in the pregnant ewe and the fetus (15) and to those reported in the fetus after $24 \mathrm{~h}$ of direct i.v. infusion of the fetus with low doses of dexamethasone (10).

Basal pituitary-adrenal function. Maternal dexamethasone transiently depressed both maternal and fetal plasma concentrations of cortisol in the present study without any apparent alteration in plasma ACTH concentrations, consistent with 
Table 2. Arterial blood gas and metabolic status during $\mathrm{H} 1$ and $\mathrm{H} 2$ in saline- and dexamethasone-treated fetuses

\begin{tabular}{|c|c|c|c|c|c|c|}
\hline & \multicolumn{2}{|c|}{ Baseline } & \multicolumn{2}{|c|}{ Hypoxemia } & \multicolumn{2}{|c|}{ Recovery } \\
\hline \multicolumn{7}{|l|}{$\mathrm{H} 1$} \\
\hline Saline & $7.36 \pm 0.01$ & $7.35 \pm 0.01$ & $7.32 \pm 0.02$ & $7.28 \pm 0.03^{*}$ & $7.24 \pm 0.02 *$ & $7.28 \pm 0.02 *$ \\
\hline Dexamethasone & $7.32 \pm 0.01$ & $7.31 \pm 0.01$ & $7.28 \pm 0.02$ & $7.18 \pm 0.02^{*} \dagger$ & $7.13 \pm 0.02^{*} \dagger$ & $7.20 \pm 0.02 * \dagger$ \\
\hline \multicolumn{7}{|l|}{$\mathrm{PaCO}_{2}(\mathrm{~mm} \mathrm{Hg})$} \\
\hline \multicolumn{7}{|l|}{$\mathrm{PaO}_{2}(\mathrm{~mm} \mathrm{Hg})$} \\
\hline Saline & $23 \pm 1$ & $23 \pm 1$ & $13 \pm 1^{*}$ & $12 \pm 1^{*}$ & $26 \pm 1$ & $24 \pm 1$ \\
\hline Dexamethasone & $24 \pm 2$ & $24 \pm 2$ & $12 \pm 1^{*}$ & $12 \pm 1 *$ & $29 \pm 2$ & $25 \pm 2$ \\
\hline \multicolumn{7}{|l|}{$\mathrm{SatHb}(\%)$} \\
\hline Saline & $61.8 \pm 3.8$ & $59.4 \pm 3.7$ & $24.6 \pm 2.3^{*}$ & $22.8 \pm 2.0^{*}$ & $60.5 \pm 3.4$ & $59.0 \pm 3.5$ \\
\hline Dexamethasone & $62.3 \pm 3.3$ & $63.1 \pm 3.3$ & $27.7 \pm 2.8^{*}$ & $25.8 \pm 2.7 *$ & $64.1 \pm 3.6$ & $61.8 \pm 3.5$ \\
\hline Saline & $32 \pm 2$ & $32 \pm 2$ & $33 \pm 2$ & $34 \pm 2$ & $32 \pm 2$ & $31 \pm 1$ \\
\hline Dexamethasone & $31 \pm 1$ & $31 \pm 1$ & $33 \pm 1$ & $33 \pm 1$ & $30 \pm 1$ & $30 \pm 1$ \\
\hline \multicolumn{7}{|l|}{$\mathrm{H} 2$} \\
\hline \multicolumn{7}{|l|}{$\mathrm{pH}_{\mathrm{a}}$} \\
\hline Saline & $7.36 \pm 0.01$ & $7.36 \pm 0.01$ & $7.31 \pm 0.01$ & $7.25 \pm 0.02 *$ & $7.21 \pm 0.03^{*}$ & $7.27 \pm 0.04 *$ \\
\hline Dexamethasone & $7.33 \pm 0.02$ & $7.33 \pm 0.02$ & $7.28 \pm 0.03$ & $7.20 \pm 0.04^{*}$ & $7.15 \pm 0.04^{*}$ & $7.21 \pm 0.03 *$ \\
\hline \multicolumn{7}{|l|}{$\mathrm{PaCO}_{2}(\mathrm{~mm} \mathrm{Hg})$} \\
\hline Saline & $52 \pm 1$ & $52 \pm 1$ & $52 \pm 2$ & $51 \pm 1$ & $50 \pm 1$ & $50 \pm 1$ \\
\hline Dexamethasone & $52 \pm 1$ & $52 \pm 1$ & $53 \pm 1$ & $52 \pm 1$ & $48 \pm 2$ & $50 \pm 1$ \\
\hline \multicolumn{7}{|l|}{$\mathrm{PaO}_{2}(\mathrm{~mm} \mathrm{Hg})$} \\
\hline Saline & $22 \pm 1$ & $23 \pm 1$ & $12 \pm 1^{*}$ & $12 \pm 1^{*}$ & $26 \pm 2$ & $24 \pm 2$ \\
\hline Dexamethasone & $23 \pm 2$ & $23 \pm 1$ & $12 \pm 1^{*}$ & $13 \pm 1^{*}$ & $26 \pm 2$ & $24 \pm 2$ \\
\hline \multicolumn{7}{|l|}{ SatHb $(\%)$} \\
\hline \multicolumn{7}{|l|}{$[\mathrm{Hb}](\mathrm{g} / \mathrm{dL})$} \\
\hline \multicolumn{7}{|l|}{ Het $(\%)$} \\
\hline
\end{tabular}

Values are means \pm S.E.M. for 7 saline and 10 dexamethasone treated ewes. Arterial blood samples were taken at 15 and 45 minutes of normoxia (N), hypoxemia $(\mathrm{H})$ and recovery $(\mathrm{R})$. Statistical differences $(\mathrm{P}<0.05)$ are; *versus normoxia and $\dagger$ versus saline (Two Way repeated measures $(\mathrm{RM})$ ANOVA + Tukey test). Blood gas values were corrected to $39.5^{\circ} \mathrm{C} . \mathrm{pH}_{\mathrm{a}}$, arterial $\mathrm{pH}$; SatHb, saturation of hemoglobin; [Hb], concentration of hemoglobin; Hct, hematocrit.

previous studies of maternal (15) and fetal (10) treatment with synthetic glucocorticoids. The anterior pituitary and hypothalamus contain glucocorticoid receptors (16) and are responsive to cortisol negative feedback during late gestation under basal $(17,18)$ and stimulated conditions $(1,19)$. Because dexamethasone has 7 -fold greater affinity for glucocorticoid receptors than cortisol (2), its actions on hypothalamic and pituitary glucocorticoid receptors may account for potent feedback inhibition of maternal and fetal basal plasma concentrations of cortisol in this study.

At least two mechanisms may explain the lack of significant differences in basal plasma concentrations of ACTH. First, the tendency of ACTH to be lower, despite falling outside statistical significance, may be sufficient to induce significant suppression of endogenous adrenocortical glucocorticoid output in the mother and the fetus. Second, in the fetus, dexamethasone may alter pro-opiomelanocortin (POMC) processing and the ratio of biologic:immunologic ACTH released from the ante- rior pituitary. Both precursors and ACTH are present in $(20,21)$ and secreted from $(22,23)$ the ovine fetal pituitary during late gestation. Changes in the ratio of bioactive to immunoreactive ACTH secreted by pituitary cells have been observed in response to cortisol both in vivo (24) and in vitro $(25,26)$. In addition, the higher molecular weight precursors POMC and pro-ACTH have been shown to inhibit the cortisol response to ACTH in ovine fetal adrenal cells in vitro $(22,27)$. Because the ACTH antibody used in this study binds to the 1- to 24-amino acid sequence common to POMC and pro-ACTH and its processed, bioactive form ACTH, the values in this study represent both bioactive ACTH and its higher molecular weight precursors.

Other aspects of HPA axis feedback regulation that may be altered by dexamethasone include an effect on corticosteroidbinding globulin $(\mathrm{CBG})$. The presence of $\mathrm{CBG}$ maintains relatively low free cortisol concentrations close to term, and this has been suggested to reduce the degree of cortisol- 
Maternal Plasma [ACTH] During Hypoxemia 1

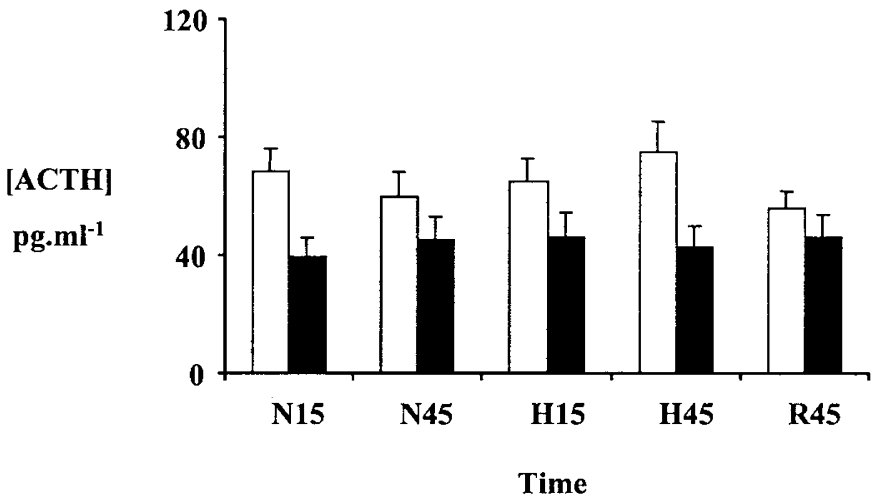

Maternal Plasma [Cortisol] During Hypoxemia 1

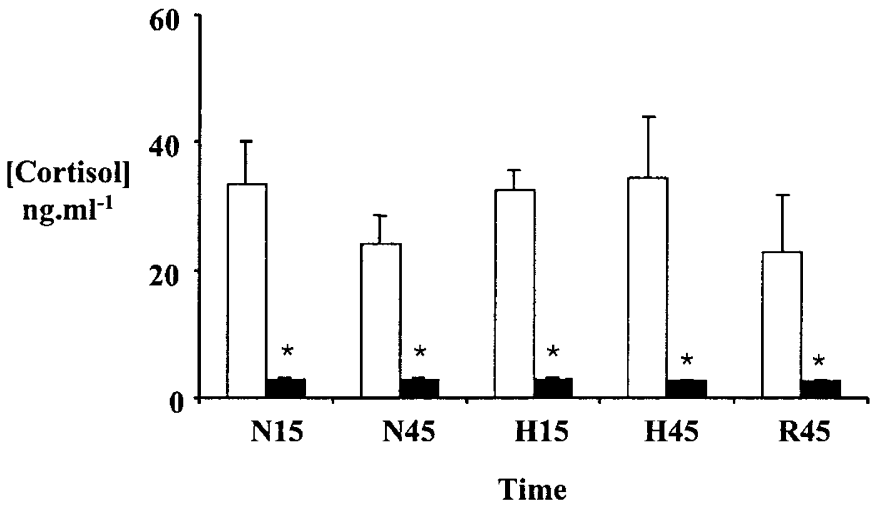

Maternal Plasma [ACTH] During Hypoxemia 2

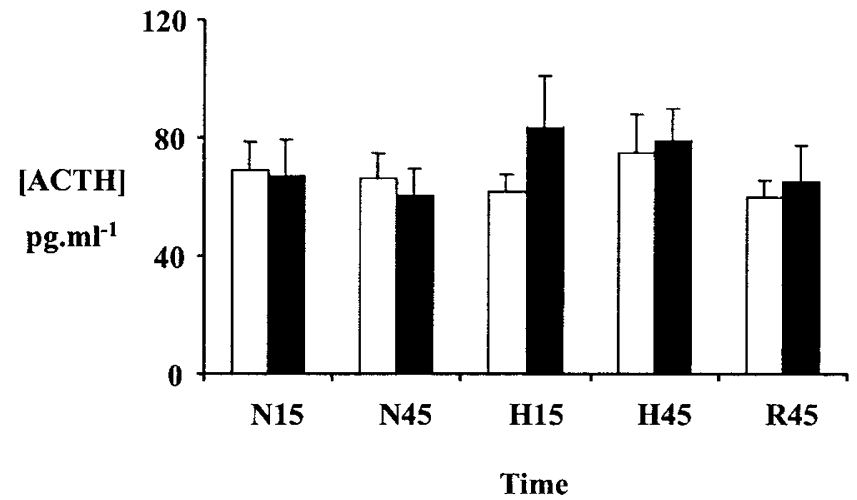

Maternal Plasma [Cortisol] During Hypoxemia 2

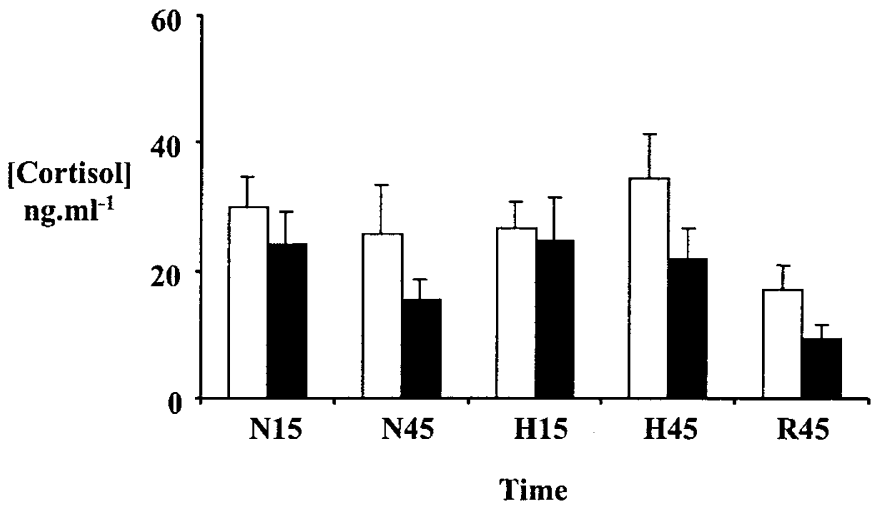

Figure 1. Plasma concentrations of ACTH and cortisol during $\mathrm{H} 1(A)$ and $\mathrm{H} 2(B)$ in saline- and dexamethasone-treated ewes. Values are means \pm SEM for seven saline-treated $(\square)$ and 10 dexamethasone-treated $(\square)$ ewes. Arterial blood samples were taken at 15 and 45 min of normoxia (N), hypoxemia (H), and recovery $(\mathrm{R}) . * p<0.05 v s$ saline (two-way repeated measures ANOVA + Tukey test).

mediated negative feedback on pituitary gland ACTH output (28). Cortisol stimulates an increase in CBG in the fetal circulation by altering expression in the fetal liver and modifying the extent of CBG glycosylation in a way that would reduce metabolic clearance (28). Sloboda et al. (29) demonstrated increased levels of plasma CBG in the umbilical cord of sheep at $7 \mathrm{~d}$ after the end of a course of repeated maternal betamethasone injections. Similar persistence of increased levels of CBG may contribute to the increase in fetal HPA axis in the period after dexamethasone treatment in the current study.

Pituitary-adrenal responses during acute hypoxemia. Hypoxemia-induced increases in fetal plasma concentrations of ACTH and cortisol, appropriate for the degree of hypoxemia and the gestational age of the fetus (10,30-33), were prevented by maternal dexamethasone, consistent with previous studies in fetal sheep $(10,34,35)$. Both direct fetal i.v. infusion with dexamethasone (10) and dexamethasone implants near the paraventricular nucleus (36) abolished the ACTH and cortisol responses to acute hypoxemia in the ovine fetus during late gestation. Likewise, dexamethasone significantly suppressed systemic corticotrophin-releasing factor and AVP stimulated ACTH and cortisol responses in fetal sheep (35).

In dexamethasone animals in the present study, basal and stimulated plasma ACTH and cortisol concentrations were similar to saline controls after the dexamethasone had cleared from the maternal and the fetal circulations, consistent with previous studies in lambs (37), adult sheep (38), and human neonates (39-41). Conversely, Fletcher et al. (9) reported not only restored but also enhanced ACTH responses to acute hypoxemia $2 \mathrm{~d}$ after cessation of direct fetal treatment with low doses of dexamethasone. Further studies of the HPA axis have shown a tendency toward hypoactivity at $1 \mathrm{y}$ of age and hyperactivity of the axis at $3 \mathrm{y}$ of age (42) in sheep. In the present study, a lack of significant differences in HPA function between dexamethasone and control fetuses $3 \mathrm{~d}$ after the second maternal injection therefore may represent simple withdrawal of glucocorticoid negative feedback or an insufficient period for manifestation of dexamethasone-induced maturation and/or resetting of the HPA axis.

Because significant reductions in arterial $\mathrm{Po}_{2}$ occurred in both ewes and their fetuses, the lack of maternal HPA axis response is unlikely to reflect differences in the severity of the challenge but rather differences in maternal and fetal sensitivity to acute hypoxemia. In addition, although it is known that the ovine placenta is not permeable to ACTH (43) and that maternal cortisol is metabolized in the placenta by the enzyme 11 $\beta$-hydroxysteroid dehydrogenase (44), the absence of any significant alterations in maternal plasma ACTH and cortisol 
Fetal Plasma [ACTH] During Hypoxemia 1

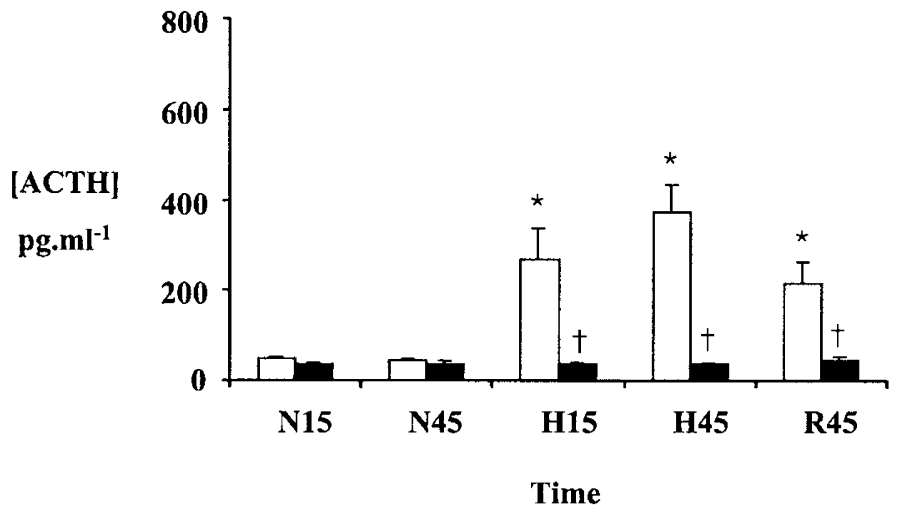

Fetal Plasma [Cortisol] During Hypoxemia 1

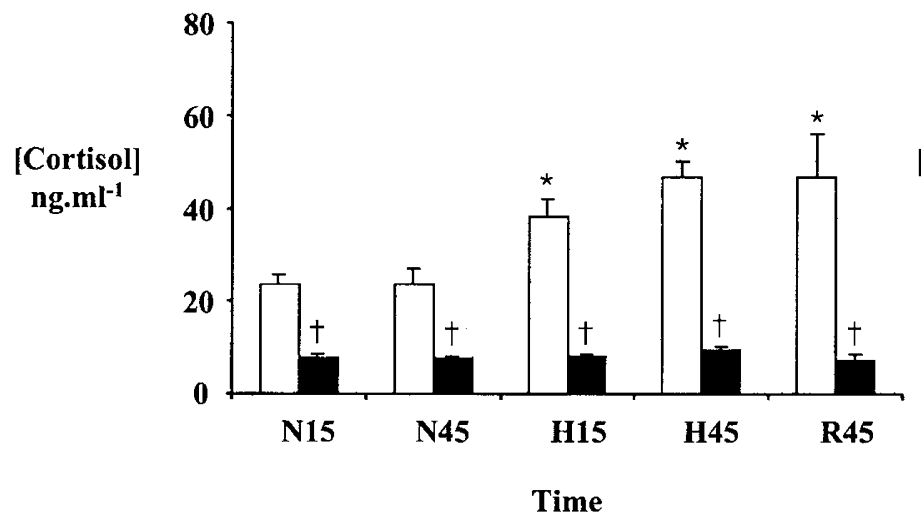

Fetal Plasma [ACTH] During Hypoxemia 2

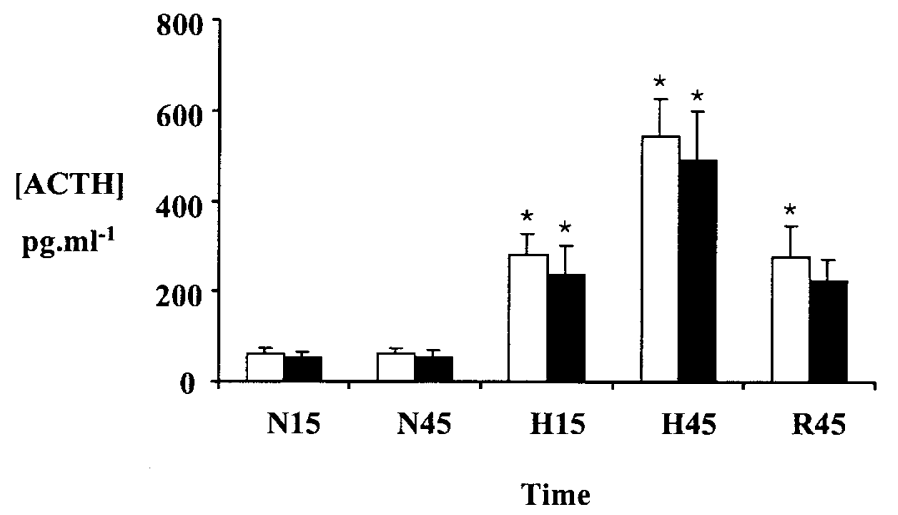

Fetal Plasma [Cortisol] During Hypoxemia 2

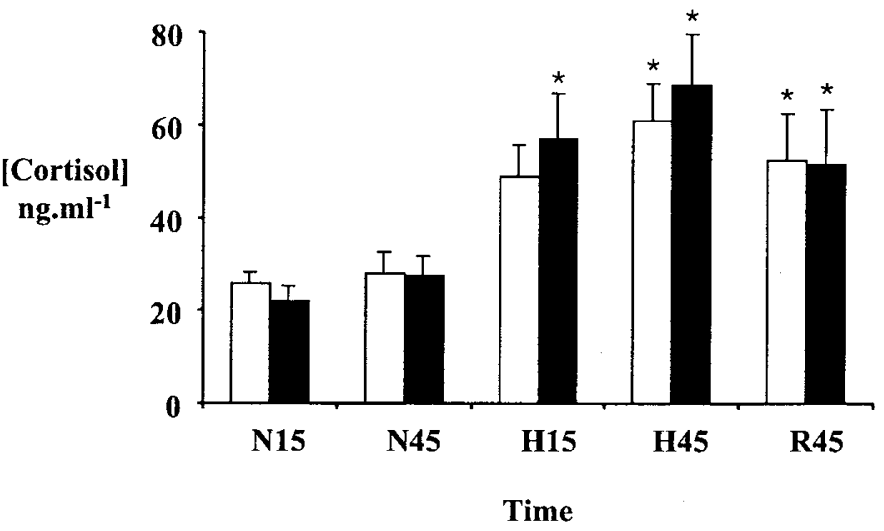

Figure 2. Plasma concentrations of ACTH and cortisol during $\mathrm{H} 1(A)$ and $\mathrm{H} 2(B)$ in saline- and dexamethasone-treated fetuses. Values are means \pm SEM for seven saline-treated $(\square)$ and 10 dexamethasone-treated $(\square)$ fetuses. Arterial blood samples were taken at 15 and 45 min of normoxia (N), hypoxemia (H), and recovery (R). ${ }^{*} p<0.05 v s$ normoxia and ${ }^{\dagger} p<0.05$ s saline (two-way repeated measures ANOVA + Tukey test).

concentrations confirms the fetal origin of the alterations in ACTH and cortisol in response to acute hypoxemia in fetal plasma.

Previous studies have suggested a role for the splanchnic sympathetic nerves innervating the adrenal gland in the steroidogenic response to stress, because stimulation of the splanchnic nerves doubled and section of these nerves halved the increase in plasma concentrations of cortisol in response to exogenous ACTH in conscious, hypophysectomized calves $(45,46)$ and lambs $(47)$. Similarly, the increase in plasma concentrations of cortisol in response to acute hypoxemia were attenuated or completely abolished in carotid chemodenervated sheep (33) and llama (48) fetuses, respectively. Hence, Giussani et al. (33) suggested that in the fetus during late gestation, a reflex arc triggered by the carotid chemoreceptors and mediated by splanchnic nerve efferents may increase cortisol secretion either during acute hypoxemic stress directly and/or by enhancing the sensitivity of the adrenal cortex to circulating ACTH. In the present study, the lack of an increase in plasma cortisol in the absence of an increase in plasma ACTH during $\mathrm{H} 1$ does not support a direct role for the splanchnic nerves in inducing adrenocortical cortisol secretion. Rather, these data support the hypothesis that splanchnic nerve efferents may increase cortisol secretion during acute stress by enhancing the sensitivity of the adrenal cortex to the prevailing plasma concentration of ACTH. Alternatively, dexamethasoneinduced negative feedback at the level of the adrenal gland itself may suppress both neural and endocrine regulation of adrenal cortisol secretion.

Activation of the HPA axis is integral to the fetal defense response to acute hypoxemic stress, a physiologic challenge that is common during labor and delivery (8). In the present study, maternal administration of dexamethasone in doses and dose intervals used in human clinical practice significantly suppressed fetal HPA axis activation in response to an acute hypoxemic challenge that occurred during but not $3 \mathrm{~d}$ after treatment. The results of the present study therefore suggest that the timing of an episode of acute hypoxemia in relation to maternal administration of synthetic glucocorticoids may determine the capacity of the fetal pituitary-adrenal axis to respond to the challenge. Furthermore, an increase in plasma concentrations of cortisol is essential for mobilization of fuel reserves at birth to maintain a supply of oxidative substrates during the transition from parenteral to enteral nutrition (5). Suppression of the HPA axis at the time of delivery therefore may have adverse consequences for the immediate adaptation 

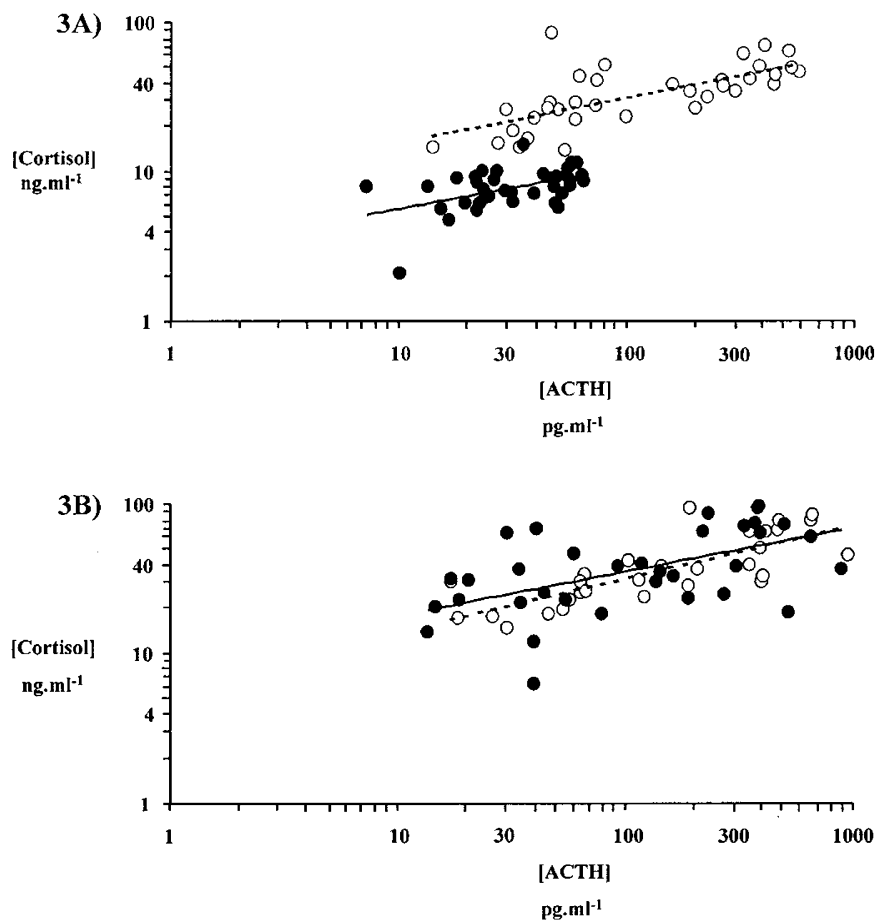

Figure 3. Linear regression of fetal plasma ACTH and cortisol concentrations during $\mathrm{H} 1(A)$ and $\mathrm{H} 2(B)$ in saline $(O)$ and dexamethasone $(\bullet)$ treated fetuses. Data points are for all paired ACTH and cortisol samples in individual fetuses obtained during $\mathrm{H} 1(A)$ or $\mathrm{H} 2(B)$. There was a significant change in the intercept $(p<0.05)$ but not the slope of the relationship between plasma $\mathrm{ACTH}$ and cortisol in dexamethasone-treated fetuses during $\mathrm{H} 1$ but not $\mathrm{H} 2$. Saline H1: $\mathrm{y}=0.301 \times+0.889(n=7, r=0.689, p<0.05)$; dexamethasone $\mathrm{H} 1: \mathrm{y}=0.283 \times+0.467(n=10, r=0.479, p<0.05)$; saline H2: $\mathrm{y}=$ $0.361 \times+0.783(n=7, r=0.782, p<0.05)$; dexamethasone $\mathrm{H} 2: \mathrm{y}=$ $0.299 \times+0.957(n=10, r=0.560, p<0.05)$.

of the newborn to extrauterine life. This work, of course, does not suggest that antenatal glucocorticoid therapy should be abandoned, but it reemphasizes that repeated treatment should be discouraged and that new clinical regimens should concentrate on achieving an optimal dose that maintains the beneficial maturational effects of the steroid while minimizing the unwanted adverse side effects.

Acknowledgments. We acknowledge Paul Hughes for help during surgery and Sue Nicholls for the routine care of the animals in this study.

\section{REFERENCES}

1. Liggins GC 1969 Premature delivery of foetal lambs infused with glucocorticoids J Endocrinol 45:515-523

2. Ballard PL, Ballard RA 1995 Scientific basis and therapeutic regimens for use of antenatal glucocorticoids. Am J Obstet Gynecol 173:254-262

3. Crowley PA 1995 Antenatal corticosteroid therapy: a meta-analysis of the randomized trials, 1972 to 1994. Am J Obstet Gynecol 173:322-335

4. NIH Consensus Development Conference 1995 Effect of corticosteroids for fetal maturation on perinatal outcomes. NIH Consensus Development Panel on the Effect of Corticosteroids for Fetal Maturation on Perinatal Outcomes. JAMA 273:413-418

5. Fowden AL, Li J, Forhead AJ 1998 Glucocorticoids and the preparation for life after birth: are there long-term consequences of the life insurance? Proc Nutr Soc 57:113122

6. Crowley P 2000 Prophylactic corticosteroids for preterm birth. Cochrane Database Syst Rev CD000065

7. Giussani DA, Spencer JAD, Hanson MA 1994 Fetal cardiovascular reflex responses to hypoxaemia. Fetal Maternal Med Rev 6:17-37
8. Huch A, Huch R, Schneider H, Rooth G 1977 Continuous transcutaneous monitoring of fetal oxygen tension during labour. Br J Obstet Gynaecol 84(suppl 1):1-39

9. Fletcher AW, Ma XH, Wu WX, Nathanielsz W, McGarrigle HH, Fowden AL, Giussani DA 2004 Antenatal glucocorticoids reset the level of baseline and hypoxiainduced pituitary-adrenal activity in the sheep fetus during late gestation. Am J Physiol Endocrinol Metab 286:E311-E319

10. Fletcher AJ, Goodfellow MR, Forhead AJ, Gardner DS, McGarrigle HH, Fowden AL, Giussani DA 2000 Low doses of dexamethasone suppress pituitary-adrenal function but augment the glycemic response to acute hypoxemia in fetal sheep during late gestation. Pediatr Res 47:684-691

11. Fowden AL, Mijovic J, Silver M 1993 The effects of cortisol on hepatic and renal gluconeogenic enzyme activities in the sheep fetus during late gestation. J Endocrinol 137:213-222

12. Armitage P, Berry G 1994 Further Analysis of Straight Line Data. Statistical Methods in Medical Research. Blackwell, Oxford, pp 292-305

13. Kream J, Mulay S, Fukushima DK, Solomon S 1983 Determination of plasma dexamethasone in the mother and the newborn after administration of the hormone in a clinical trial. J Clin Endocrinol Metab 56:127-133

14. Petersen MC, Nation RL, Ashley JJ, McBride WG 1980 The placental transfer of betamethasone. Eur J Clin Pharmacol 18:245-247

15. Bennet L, Kozuma S, McGarrigle HH, Hanson MA 1999 Temporal changes in fetal cardiovascular, behavioural, metabolic and endocrine responses to maternally administered dexamethasone in the late gestation fetal sheep. Br J Obstet Gynaecol 106:331-339

16. Yang K, Jones SA, Challis JR 1990 Changes in glucocorticoid receptor number in the hypothalamus and pituitary of the sheep fetus with gestational age and after adrenocorticotropin treatment. Endocrinology 126:11-17

17. McMillen IC, Antolovich GC, Mercer JE, Perry RA, Silver M 1990 Proopiomelanocortin messenger RNA levels are increased in the anterior pituitary of the sheep fetus after adrenalectomy in late gestation. Neuroendocrinology 52:297-302

18. Myers DA, Ding XY, Nathanielsz PW 1991 Effect of fetal adrenalectomy on messenger ribonucleic acid for proopiomelanocortin in the anterior pituitary and for corticotropin-releasing hormone in the paraventricular nucleus of the ovine fetus. Endocrinology 128:2985-2991

19. Ozolins IZ, Young IR, McMillen IC 1990 Effect of cortisol infusion on basal and corticotropin-releasing factor (CRF)-stimulated plasma ACTH concentrations in the sheep fetus after surgical isolation of the pituitary. Endocrinology 127:1833-1840

20. Fora MA, Butler TG, Rose JC, Schwartz J 1996 Adrenocorticotropin secretion by fetal sheep anterior and intermediate lobe pituitary cells in vitro: effects of gestation and adrenalectomy. Endocrinology 137:3394-3400

21. Fora MA, Valego NK, Lively MO, Castro MI, Rose JC 1996 ACTH-like bioactivity and immunoactivity in fetal lamb pituitaries at 0.65 and 0.95 gestation. Reprod Fertil Dev 8:195-201

22. Schwartz J, Kleftogiannis F, Jacobs R, Thorburn GD, Crosby SR, White A 1995 Biological activity of adrenocorticotropic hormone precursors on ovine adrenal cells. Am J Physiol 268:E623-E629

23. Zehnder TJ, Valego NK, Schwartz J, White A, Rose JC 1995 Regulation of bioactive and immunoreactive ACTH secretion by CRF and AVP in sheep fetuses. Am J Physiol 269:E1076-E1082

24. Zehnder TJ, Valego NK, Schwartz J, Green J, Rose JC 1998 Cortisol infusion depresses the ratio of bioactive to immunoreactive ACTH in adrenalectomized sheep fetuses. Am J Physiol 274:E391-E396

25. McMillen IC, Merei JJ, White A, Crosby S, Schwartz J 1995 Increasing gestational age and cortisol alter the ratio of ACTH precursors: ACTH secreted from the anterior pituitary of the fetal sheep. J Endocrinol 144:569-576

26. Schwartz J, Ash P, Ford V, Raff H, Crosby S, White A 1994 Secretion of adrenocorticotrophin (ACTH) and ACTH precursors in ovine anterior pituitary cells: actions of corticotrophin-releasing hormone, arginine vasopressin and glucocorticoids. J Endocrinol 140:189-195

27. Roebuck MM, Jones CT, Holland D, Silman R 1980 In vitro effects of high molecular weight forms of ACTH on the fetal sheep adrenal. Nature 284:616-618

28. Berdusco ET, Yang K, Hammond GL, Challis JR 1995 Corticosteroid-binding globulin (CBG) production by hepatic and extra-hepatic sites in the ovine fetus; effects of CBG on glucocorticoid negative feedback on pituitary cells in vitro. J Endocrinol 146:121-130

29. Sloboda DM, Newnham JP, Challis JR 2000 Effects of repeated maternal betamethasone administration on growth and hypothalamic-pituitary-adrenal function in the ovine fetus at term. J Endocrinol 165:79-91

30. Akagi K, Challis JR 1990 Hormonal and biophysical responses to acute hypoxemia in fetal sheep at 0.7-0.8 gestation. Can J Physiol Pharmacol 68:1527-1532

31. Akagi K, Challis JR 1990 Threshold of hormonal and biophysical responses to acute hypoxemia in fetal sheep at different gestational ages. Can J Physiol Pharmacol 68:549-555

32. Boddy K, Dawes GS, Fisher R, Pinter S, Robinson JS 1974 Foetal respiratory movements, electrocortical and cardiovascular responses to hypoxaemia and hypercapnia in sheep. J Physiol 243:599-618

33. Giussani DA, McGarrigle HH, Moore PJ, Bennet L, Spencer JA, Hanson MA 1994 Carotid sinus nerve section and the increase in plasma cortisol during acute hypoxia in fetal sheep. J Physiol 477:75-80

34. Matthews SG, Challis JR 1995 Levels of pro-opiomelanocortin and prolactin mRNA in the fetal sheep pituitary following hypoxaemia and glucocorticoid treatment in late gestation. J Endocrinol 147:139-146

35. Norman LJ, Challis JR 1987 Dexamethasone inhibits ovine corticotrophin-releasing factor (oCRF), arginine vasopressin (AVP), and oCRF + AVP stimulated release of ACTH during the last third of pregnancy in the sheep fetus. Can J Physiol Pharmacol 65:1186-1192 
36. McDonald TJ, Hoffmann GE, Myers DA, Nathanielsz PW 1990 Hypothalamic glucocorticoid implants prevent fetal ovine adrenocorticotropin secretion in response to stress. Endocrinology 127:2862-2868

37. Dodic M, May CN, Wintour EM, Coghlan JP 1998 An early prenatal exposure to excess glucocorticoid leads to hypertensive offspring in sheep. Clin Sci (Lond) 94:149-155

38. Dodic M, Peers A, Moritz K, Hantzis V, Wintour EM 2002 No evidence for HPA reset in adult sheep with high blood pressure due to short prenatal exposure to dexamethasone. Am J Physiol Regul Integr Comp Physiol 282:R343-R350

39. Ford LR, Willi SM, Hollis BW, Wright NM 1997 Suppression and recovery of the neonatal hypothalamic-pituitary-adrenal axis after prolonged dexamethasone therapy. J Pediatr 131:722-726

40. Terrone DA, Rinehart BK, Rhodes PG, Roberts WE, Miller RC, Martin JN Jr 1999 Multiple courses of betamethasone to enhance fetal lung maturation do not suppress neonatal adrenal response. Am J Obstet Gynecol 180:1349-1353

41. Terrone DA, Smith LG Jr, Wolf EJ, Uzbay LA, Sun S, Miller RC 1997 Neonata effects and serum cortisol levels after multiple courses of maternal corticosteroids. Obstet Gynecol 90:819-823
42. Sloboda DM, Moss TJ, Gurrin LC, Newnham JP, Challis JR 2002 The effect of prenatal betamethasone administration on postnatal ovine hypothalamic-pituitaryadrenal function. J Endocrinol 172:71-81

43. Jones CT, Luther E, Ritchie JW, Worthington D 1975 The clearance of ACTH from the plasma of adult and fetal sheep. Endocrinology 96:231-234

44. Murphy BE, Clark SJ, Donald IR, Pinsky M, Vedady D 1974 Conversion of maternal cortisol to cortisone during placental transfer to the human fetus. Am J Obste Gynecol 118:538-541

45. Edwards AV, Jones CT 1987 The effect of splanchnic nerve section on the sensitivity of the adrenal cortex to adrenocorticotrophin in the calf. J Physiol 390:23-31

46. Edwards AV, Jones CT 1987 The effect of splanchnic nerve stimulation on adrenocortical activity in conscious calves. J Physiol 382:385-396

47. Edwards AV, Jones CT, Bloom SR 1986 Reduced adrenal cortical sensitivity to ACTH in lambs with cut splanchnic nerves. J Endocrinol 110:81-85

48. Riquelme RA, Llanos JA, McGarrigle HH, Sanhueza EM, Hanson MA, Giussan DA 1998 Chemoreflex contribution to adrenocortical function during acute hypoxemia in the llama fetus at 0.6 to 0.7 of gestation. Endocrinology 139:25642570 